\title{
Treatment with the Oral Antidiabetic Agent Troglitazone Improves $\beta$ Cell Responses to Glucose in Subjects with Impaired Glucose Tolerance
}

\author{
Melissa K. Cavaghan, David A. Ehrmann, Maria M. Byrne, and Kenneth S. Polonsky \\ Department of Medicine, The University of Chicago and Pritzker School of Medicine, Chicago, Illinois 60637
}

\begin{abstract}
Impaired glucose tolerance (IGT) is associated with defects in both insulin secretion and action and carries a high risk for conversion to non-insulin-dependent diabetes mellitus (NIDDM). Troglitazone, an insulin sensitizing agent, reduces glucose concentrations in subjects with NIDDM and IGT but is not known to affect insulin secretion. We sought to determine the role of $\beta$ cell function in mediating improved glucose tolerance. Obese subjects with IGT received 12 wk of either $400 \mathrm{mg}$ daily of troglitazone $(n=14)$ or placebo $(n=7)$ in a randomized, double-blind design. Study measures at baseline and after treatment were glucose and insulin responses to a 75-g oral glucose tolerance test, insulin sensitivity index $\left(\mathrm{S}_{\mathrm{I}}\right)$ assessed by a frequently sampled intravenous glucose tolerance test, insulin secretion rates during a graded glucose infusion, and $\beta$ cell glucose-sensing ability during an oscillatory glucose infusion. Troglitazone reduced integrated glucose and insulin responses to oral glucose by $10 \%(P=0.03)$ and $39 \%(P=0.003)$, respectively. $S_{I}$ increased from $1.3 \pm 0.3$ to $2.6 \pm 0.4 \times 10^{-5} \mathrm{~min}^{-1} \mathrm{pM}^{-1}(P=$ 0.005). Average insulin secretion rates adjusted for $S_{I}$ over the glucose interval $5-11 \mathrm{mmol} /$ liter were increased by $52 \%$ $(P=0.02)$, and the ability of the $\beta$ cell to entrain to an exogenous oscillatory glucose infusion, as evaluated by analysis of spectral power, was improved by $49 \%(P=0.04)$. No significant changes in these parameters were demonstrated in the placebo group. In addition to increasing insulin sensitivity, we demonstrate that troglitazone improves the reduced $\beta$ cell response to glucose characteristic of subjects with IGT. This appears to be an important factor in the observed improvement in glucose tolerance. (J. Clin. Invest. 1997. 100: 530-537.) Key words: thiazoles • insulin resistance • insulin secretion • non-insulin-dependent diabetes mellitus • glucose intolerance
\end{abstract}

\section{Introduction}

Impaired glucose tolerance (IGT) ${ }^{1}$ is a condition associated with elevations in the plasma glucose concentration above 7.8 $\mathrm{mmol} /$ liter $120 \mathrm{~min}$ after ingestion of a 75-g glucose load (standard oral glucose tolerance test). Although greater than nor-

Address correspondence to Kenneth Polonsky, M.D., University of Chicago, Department of Medicine, 5841 S. Maryland Ave., MC 1027, Chicago, IL 60637. Phone: 773-702-6217; FAX: 773-834-0846; E-mail: polonsky@medicine.bsd.uchicago.edu

Received for publication 6 February 1997 and accepted in revised form 22 April 1997.

J. Clin. Invest.

(C) The American Society for Clinical Investigation, Inc. 0021-9738/97/08/0530/08 \$2.00

Volume 100, Number 3, August 1997, 530-537

http://www.jci.org mal, these concentrations are not sufficiently elevated to meet the criteria established for the diagnosis of diabetes (1). In view of the high proportion of subjects with IGT that go on to develop overt diabetes (2), however, it may be considered a prediabetic condition. For this reason there is considerable interest in exploring therapeutic approaches that will reduce the risk of diabetes in subjects with IGT. A large prospective multicenter study in the United States, the Diabetes Prevention Program, is examining this question.

From a pathophysiologic standpoint, IGT is characterized by the presence of insulin resistance (3-6), and as we and others have demonstrated, subtle defects in $\beta$ cell function (7-9). These latter defects consist of a relative inability to detect and respond to small changes in the plasma glucose concentration induced by oscillatory infusions of exogenous glucose and mild shifts to the right in the dose-response curves relating the plasma glucose concentration to the insulin secretion rate $(8$, 9). It has been demonstrated previously that a number of therapeutic interventions can improve glucose tolerance in subjects with IGT, including weight loss $(10,11)$, treatment with sulfonylureas $(11,12)$, the biguanide drug metformin $(13,14)$, and more recently the thiazolidinediones (15-17). Thiazolidinediones have been proposed to act primarily as insulin sensitizers since they improve hepatic and peripheral insulin resistance and lower triglycerides and free fatty acids (15, 17-20). Although the thiazolidinediones do not appear to be insulin secretagogues (21), we have observed in the Zucker diabetic fatty rat, an animal model of non-insulin-dependent diabetes mellitus (NIDDM), that if administered before the onset of diabetes, these drugs can prevent the deterioration in $\beta$ cell function that is associated with overt disease $(22,23)$. Whether such beneficial effects on $\beta$ cell function occur in humans has not been determined. The present study was therefore undertaken to determine whether treatment of subjects who have IGT or mild diabetes with troglitazone would affect the underlying defects in $\beta$ cell function.

\section{Methods}

\section{Subjects}

The study design was that of a double blind, placebo-controlled clinical trial in which two subjects were assigned to treatment with troglitazone for every one subject treated with placebo. Randomization was performed by Parke-Davis Pharmaceutical Research Division, Warner Lambert Co. (Ann Arbor, MI), who kindly provided the study medication and placebo. The groups were well matched for age, degree of obesity, and extent of glucose intolerance (for all compari-

1. Abbreviations used in this paper: $\mathrm{AIR}_{\mathrm{Gluc}}$, acute insulin response to glucose; AUC, area under the curve; IGT, impaired glucose tolerance; ISR, insulin secretion rate; FSIVGTT, frequently sampled intravenous glucose tolerance test; NIDDM, non-insulin-dependent diabetes mellitus; $\operatorname{PPAR} \gamma$, peroxisome proliferator-activated receptor gamma; $\mathrm{S}_{\mathrm{I}}$, insulin sensitivity index. 
Table I. Subject Characteristics

\begin{tabular}{lcc}
\hline & Troglitazone & Placebo \\
\hline & $n=14$ & $n=7$ \\
Age (yr) & $46 \pm 4$ & $42 \pm 4$ \\
Sex (M/F) & $3 / 11$ & $0 / 7$ \\
Weight (kg) & $101 \pm 4$ & $106 \pm 5$ \\
BMI (kg/m $\left.{ }^{2}\right)$ & $35.7 \pm 1.6$ & $38.9 \pm 2.3$ \\
Waist/Hip ratio & $0.92 \pm 0.02$ & $0.89 \pm 0.04$ \\
Glycoslylated Hgb (\%) & $6.4 \pm 0.3$ & $6.0 \pm 0.2$ \\
Fasting glucose (mmol/liter) & $5.6 \pm 0.2$ & $5.4 \pm 0.2$ \\
Fasting insulin (pmol/liter) & $169 \pm 32$ & $171 \pm 42$ \\
\end{tabular}

sons, $P=\mathrm{NS}$ ). At entry, fasting plasma glucose concentrations (5.6 \pm 0.2 vs. $5.4 \pm 0.2 \mathrm{mmol} / \mathrm{liter}, P=\mathrm{NS}$ ) and glycosylated hemoglobin concentrations $(6.4 \pm 0.3$ vs. $6.0 \pm 0.2 \%, P=\mathrm{NS})$ were similar in the troglitazone and placebo groups. All subjects were at least $20 \%$ above ideal body weight, and none of the subjects was receiving current treatment for diabetes. 26 subjects enrolled in the study. Three subjects withdrew because they were unable to return for the physiological testing on treatment, and two subjects in the placebo group withdrew because they developed symptoms of headache and diarrhea that they assumed were due to active drug. 21 subjects therefore completed the study, and their clinical characteristics are shown in Table I. All subjects had normal fasting glucose levels and met World Health Organization criteria for IGT or mild diabetes after a 75-g oral glucose tolerance test (1). The study protocol was approved by the Institutional Review Board at the University of Chicago, and all subjects gave written informed consent.

\section{Study protocols}

All subjects underwent four separate protocols designed to test changes in glucose tolerance, insulin secretion, and insulin action before and after $12 \mathrm{wk}$ of treatment with either troglitazone, $400 \mathrm{mg}$ orally per d, or placebo. Subjects were asked to maintain a consistent diet and activity level throughout the study. Non-study medications were kept at a constant dose. Subjects were questioned for adverse effects by telephone, and hepatic and hematologic profiles were monitored at 6 and 12 wk. Compliance, as assessed by pill counting, was $96 \%$ in the troglitazone group and $98 \%$ in the placebo group, $P=$ NS. All studies were performed in the Clinical Research Center at the University of Chicago after an overnight fast with the subjects in the recumbent position. Intravenous cannulas were placed in a forearm vein for blood withdrawal, and the forearm was warmed to arterialize the venous sample. When necessary, a second catheter was placed for administration of glucose, insulin, or tolbutamide as described below.

Oral glucose tolerance test. Glucose and insulin concentrations were measured in plasma and serum respectively before and every 30 min for $180 \mathrm{~min}$ after ingestion of $75 \mathrm{~g}$ of glucose.

Frequently sampled intravenous glucose tolerance test (FSIVGTT). To define insulin sensitivity and the acute insulin response to glucose as described by Bergman (24), glucose and insulin concentrations were measured after an intravenous bolus of glucose $(300 \mathrm{mg} / \mathrm{kg})$ followed 20 min later by a bolus of tolbutamide $\left(125 \mathrm{mg} / \mathrm{m}^{2}\right.$; Pharmacia, Piscataway, NJ, and Upjohn, Kalamazoo, MI). Two subjects did not receive tolbutamide because of a history of sulfa allergy.

Graded glucose infusion. To define the insulin secretory response to an increasing plasma glucose concentration, subjects received graded intravenous infusions of glucose at progressively increasing rates $(1,2,3,4,6$, and $8 \mathrm{mg} / \mathrm{kg}$ per $\mathrm{min})$ as we have previously described $(25,26)$. Each glucose infusion rate was administered for a total of $40 \mathrm{~min}$. Glucose, insulin, and C-peptide levels were measured at 10-min intervals during a 40-min baseline period and throughout the 240-min glucose infusion. This protocol raised the plasma glucose concentration from basal to mildly hyperglycemic levels. If the fasting glucose level was greater than $5 \mathrm{mmol} / \mathrm{liter}$, a small dose of insulin $(0.007 \mathrm{U} / \mathrm{kg}$, followed by a low-dose continuous infusion) was administered intravenously to lower the glucose to $5 \mathrm{mmol} / \mathrm{liter}$, an intervention designed to ensure consistent basal glucose levels at the start of the study. We have previously shown that this small dose of insulin does not interfere with the subsequent insulin secretory response (25). The exogenous insulin was allowed to decay for $20 \mathrm{~min}$ before the above protocol was started.

Oscillatory glucose infusion. This protocol was performed immediately after the graded glucose infusion as previously described and is designed to determine if the $\beta$ cell can detect and respond appropriately to oscillations in the plasma glucose concentration (27). Dextrose ( $20 \%$ solution) was infused intravenously in an oscillatory pattern for $16 \mathrm{~h}$ by a computer-directed infusion pump at an average rate of $6 \mathrm{mg} / \mathrm{kg}$ per min. The computer was programmed to deliver the glucose in an oscillatory pattern with a period of $144 \mathrm{~min}$ and an amplitude of $33 \%$ above and below the average infusion rate. After initiation of the glucose infusion, $4 \mathrm{~h}$ was allowed for equilibration of glucose levels during which time blood samples were not collected. Thereafter, sampling occurred at 15-min intervals during the final $12 \mathrm{~h}$ of the study for measurement of glucose, C-peptide, and insulin.

Assays

Insulin levels were measured in serum by a double antibody technique (28). The lower limit of detection was $20 \mathrm{pmol} / \mathrm{liter}$, and the average intra-assay coefficient of variation was $6 \%$. C-peptide levels were assayed on plasma (29), with a lower detection limit of 0.02 $\mathrm{pmol} /$ liter and intraassay coefficient of variation of $6 \%$. Plasma glucose was measured with the glucose oxidase technique using a YSI analyzer (Yellow Springs Instruments, Yellow Springs, $\mathrm{OH}$ ). This assay has a coefficient of variation of less than $2 \%$. Glycosylated hemoglobin was measured by boronate affinity chromatography with an intraassay coefficient of variation of $4 \%$ (BioRad, Hercules, CA).

\section{Study endpoints and data analysis}

Insulin secretion rates. Standard kinetic parameters for C-peptide clearance adjusted for age, sex, and body surface area were used (30). These parameters were used to derive the insulin secretion rate (ISR) from the plasma C-peptide concentrations by deconvolution as previously described, in each 10 - or 15-min interval between blood sampling $(31,32)$.

Glucose tolerance. Primary endpoints for the oral glucose tolerance test were fasting and 2-h glucose and insulin levels, and 180-min area under the curve (AUC) for glucose and insulin. AUC was calculated using the trapezoidal rule. Glycosylated hemoglobin was also measured before and after treatment.

Insulin sensitivity and secretion during frequently sampled intravenous glucose tolerance tests. Minimal model analysis of the data was used to derive the insulin sensitivity index, $\mathrm{S}_{\mathrm{I}}$ (calculated by the MINMOD computer program kindly provided by Dr. Richard Bergman). The acute insulin response to glucose (AIR Gluc $)$, a measure of $\beta$ cell function, was calculated as the average increment of the insulin response over baseline from 2 to $10 \mathrm{~min}$. To quantify insulin secretion independently of changes in insulin sensitivity, the product of $\mathrm{AIR}_{\text {Gluc }}$ $\times \mathrm{S}_{\mathrm{I}}$, the "disposition index," was also calculated as previously described $(33,34)$.

Relationship between glucose and insulin secretion during graded glucose infusions. These relationships were explored by analyzing the data from the graded glucose infusion studies. Baseline glucose, insulin, C-peptide, and ISRs were calculated as the mean of the values in the $-30,-20,-10$, and 0 -min samples. ISRs and glucose concentrations used in the analysis represented the average of the values between 10 and $40 \mathrm{~min}$ at each glucose infusion rate. Mean ISR for each glucose infusion rate was then plotted against the corresponding mean glucose concentration to define the dose-response relationship. From the slope of the line describing this relationship, the average ISR over each $1 \mathrm{mmol} /$ liter glucose interval from 5 to $11 \mathrm{mmol} /$ liter 
was then calculated. As above, to represent $\beta$ cell function independently of insulin sensitivity, average ISR was then adjusted by multiplying ISR by $\mathrm{S}_{\mathrm{I}}$.

Spectral analysis for oscillatory glucose infusions. Each individual ISR and glucose profile from the oscillatory glucose infusion protocol was submitted to spectral analysis to investigate whether the oscillations were entrainable as previously reported (27). Each spectrum was normalized assuming the total variance of each series to be $100 \%$ and is expressed as the normalized spectral power. Each series was detrended with the first difference filter before spectral estimates were calculated using a Tukey window of 24 data points as described by Jenkins and Watts (35).

Statistical analyses. All results are expressed as means \pm SEM. The summary measures of insulin secretion and sensitivity listed above were compared within the troglitazone and placebo groups before and after treatment using the paired two-tailed $t$ test. The statistical significance of differences was assessed at the $5 \%$ level.

\section{Results}

Clinical parameters and glycosylated hemoglobin (Table II). Degree of obesity as judged by the body mass index and body fat distribution as judged by the waist-hip ratio were not different in the two groups and did not change significantly in either group over the duration of the study. Glycosylated hemoglobin values, which were within the normal range for our laboratory $(4.5-7.2 \%)$ at the start of the study, decreased significantly in the troglitazone-treated group (6.4 \pm 0.3 to $6.0 \pm 0.3$, $P=0.01)$, but did not change in the placebo group (6.0 $\pm 0.2 \mathrm{vs}$. $5.9 \pm 0.1, P=\mathrm{NS})$.
Oral glucose tolerance test (Fig. 1 and Table II). Fasting glucose values did not differ before and after treatment in the troglitazone group ( $5.6 \pm 0.2$ vs. $5.6 \pm 0.2 \mathrm{mmol} / \mathrm{liter}, P=\mathrm{NS})$ or in the placebo group $(5.4 \pm 0.2$ vs $5.6 \pm 0.3, P=0.5 \% \mathrm{NS})$. The AUC for glucose was reduced by $10 \%$ in the troglitazone group $(P=0.03)$ and did not change in the placebo-treated group.

Fasting $(P=0.04)$ and 2 -h insulin values $(P=0.001)$ fell significantly in the troglitazone group and did not change in the placebo group (Table II). The total insulin response to glucose as judged by the area under the insulin concentration curve for $180 \mathrm{~min}$ after glucose ingestion fell by $39 \%$ in the troglitazone treatment group $(P=0.03)$ and did not change in the placebo group.

Frequently sampled intravenous glucose tolerance test. The insulin sensitivity index $\left(\mathrm{S}_{\mathrm{I}}\right)$ improved significantly in the troglitazone group $\left(1.3 \pm 0.3\right.$ to $2.6 \pm 0.4\left[\times 10^{-5} \mathrm{~min}^{-1} \mathrm{pM}^{-1}\right], P=$ $0.005)$ and did not change in the placebo group (2.0 \pm 0.3 to $1.9 \pm 0.4, P=\mathrm{NS}$ ) as summarized in Table II. Although absolute differences in $\mathrm{AIR}_{\mathrm{Gluc}}$ were not observed, the product of $\mathrm{AIR}_{\text {Gluc }}$ and $\mathrm{S}_{\mathrm{I}}$, i.e., the disposition index, improved significantly in the troglitazone group $(P=0.04)$. This reflects a relative increase in insulin response when insulin sensitivity is accounted for.

Relationship between glucose and ISR during graded glucose infusion (Figs. 2 and 3). The responses in glucose and ISR in the two groups at the beginning and end of the study are shown in Fig. 2. In this protocol glucose concentrations increased from $5.0 \pm 0.1 \mathrm{mmol} /$ liter at baseline to $13.4 \pm 0.6$ at the

Table II. Summary Measures

\begin{tabular}{|c|c|c|c|c|c|c|}
\hline & \multicolumn{3}{|c|}{ Troglitazone } & \multicolumn{3}{|c|}{ Placebo } \\
\hline & Before & After & $P$ value & Before & After & $P$ value \\
\hline BMI $\left(\mathrm{kg} / \mathrm{m}^{2}\right)$ & $35.7 \pm 1.6$ & $36.3 \pm 1.6$ & NS & $38.9 \pm 2.3$ & $39.2 \pm 2.2$ & NS \\
\hline Waist/Hip ratio & $0.92 \pm 0.02$ & $0.92 \pm 0.02$ & NS & $0.89 \pm 0.04$ & $0.87 \pm 0.03$ & NS \\
\hline Glycosylated Hgb (\%) & $6.37 \pm 0.25$ & $6.00 \pm 0.26$ & 0.01 & $6.04 \pm 0.21$ & $5.89 \pm 0.13$ & NS \\
\hline \multicolumn{7}{|l|}{ Oral glucose tolerance test } \\
\hline Fasting glucose (mmol/liter) & $5.6 \pm 0.2$ & $5.6 \pm 0.2$ & NS & $5.4 \pm 0.2$ & $5.6 \pm 0.3$ & NS \\
\hline 2-h glucose (mmol/liter) & $10.1 \pm 0.6$ & $8.9 \pm 0.7$ & 0.03 & $10.2 \pm 0.6$ & $8.6 \pm 0.6$ & NS \\
\hline Fasting insulin (pmol/liter) & $169 \pm 32$ & $111 \pm 13$ & 0.04 & $171 \pm 42$ & $156 \pm 35$ & NS \\
\hline 2-h insulin (pmol/liter) & $1499 \pm 274$ & $836 \pm 207$ & 0.001 & $1107 \pm 168$ & $964 \pm 151$ & NS \\
\hline Glucose AUC $(\mathrm{mmol} \times \mathrm{min} /$ liter $)$ & $1659 \pm 80$ & $1498 \pm 87$ & 0.03 & $1608 \pm 71$ & $1507 \pm 82$ & NS \\
\hline Insulin AUC $\left(\mathrm{pmol} \times 10^{-3} \times\right.$ min/liter $)$ & $198 \pm 33$ & $120 \pm 25$ & 0.003 & $167 \pm 31$ & $158 \pm 33$ & NS \\
\hline \multicolumn{7}{|l|}{ Intravenous glucose tolerance test } \\
\hline $\mathrm{S}_{\mathrm{I}}\left(\times 10^{-5} \mathrm{~min}^{-1} \mathrm{pM}^{-1}\right)$ & $1.3 \pm 0.3$ & $2.6 \pm 0.4$ & 0.005 & $2.0 \pm 0.3$ & $1.9 \pm 0.4$ & NS \\
\hline $\operatorname{AIR}_{\text {Gluc }}(\mathrm{pmol} \times \min /$ liter $)$ & $501 \pm 112$ & $461 \pm 109$ & NS & $526 \pm 127$ & $647 \pm 291$ & NS \\
\hline Disposition $\left(\mathrm{AIR}_{\mathrm{Gluc}} \times \mathrm{S}_{\mathrm{I}}\right)$ & $667 \pm 113$ & $1036 \pm 145$ & 0.03 & $1034 \pm 299$ & $1368 \pm 549$ & NS \\
\hline \multicolumn{7}{|l|}{ Graded glucose infusion } \\
\hline ISR over 5-11 mM glucose (pmol/min) & $3042 \pm 241$ & $2788 \pm 268$ & NS & $3102 \pm 358$ & $2962 \pm 414$ & NS \\
\hline \multicolumn{7}{|l|}{ ISR adjusted for $S_{I}$ over } \\
\hline $5-11 \mathrm{mM}$ glucose $\left(\mathrm{pmol} / \mathrm{min} \times 10^{-5} \mathrm{~min}^{-1} \mathrm{pM}^{-1}\right)$ & $4456 \pm 598$ & $6781 \pm 1065$ & 0.02 & $6534 \pm 633$ & $5729 \pm 643$ & NS \\
\hline \multicolumn{7}{|l|}{ Oscillatory glucose infusion } \\
\hline Average serum glucose (mmol/liter) & $11.0 \pm 0.6$ & $10.3 \pm 0.6$ & NS & $11.1 \pm 0.9$ & $10.8 \pm 0.9$ & NS \\
\hline Average ISR (pmol/min) & $673 \pm 44$ & $604 \pm 38$ & 0.03 & $691 \pm 88$ & $679 \pm 98$ & NS \\
\hline ISR adjusted for $S_{I}$ & $1001 \pm 121$ & $1465 \pm 195$ & 0.03 & $1464 \pm 160$ & $1359 \pm 199$ & NS \\
\hline Normalized spectral power ISR & $5.9 \pm 1.2$ & $8.8 \pm 1.3$ & 0.04 & $5.8 \pm 1.8$ & $5.8 \pm 1.9$ & NS \\
\hline Normalized spectral power $_{\text {Gluc }}$ & $16.7 \pm 0.7$ & $18.1 \pm 0.5$ & NS & $17.3 \pm 1.3$ & $17.2 \pm 1.0$ & NS \\
\hline
\end{tabular}



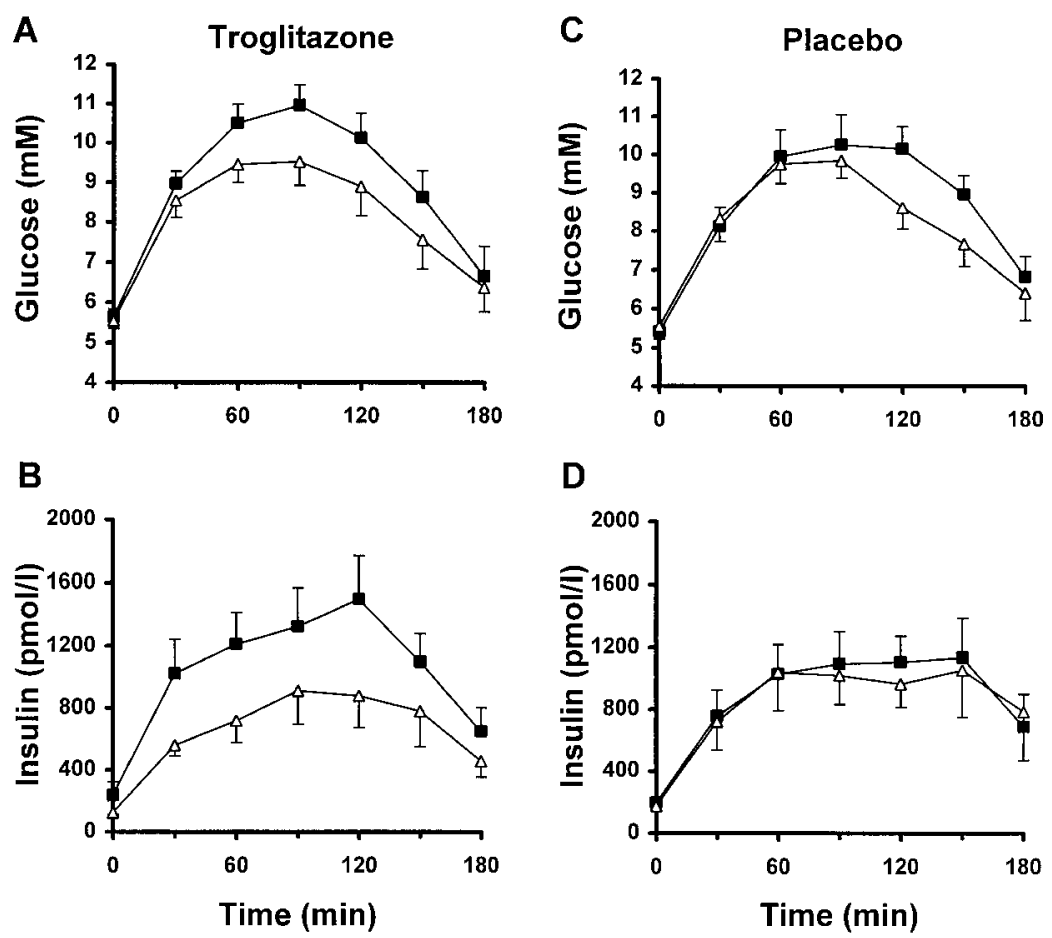

Figure 1. Mean glucose and insulin responses during oral glucose tolerance testing. Glucose $(A)$ and insulin $(B)$ responses before $(\mathbf{\square})$ and after $(\triangle)$ treatment with troglitazone (left). Glucose $(C)$ and insulin $(D)$ responses before $(\boldsymbol{\square})$ and after $(\triangle)$ placebo (right). Troglitazone reduced the area under the curve for glucose by $10 \%(P=0.03)$ and for insulin by $39 \%$ $(P=0.003)$.

end of the glucose infusion in the troglitazone group and from $5.0 \pm 0.1 \mathrm{mmol} / \mathrm{liter}$ to $13.8 \pm 0.8$ glucose in the placebo group. After treatment, maximum glucose achieved during the glucose infusion was $12.8 \pm 0.6 \mathrm{mmol} /$ liter glucose in the troglitazone group and $14.0 \pm 0.7$ in the placebo group. None of these differences was significant. Average glucose concentrations during the infusion protocols were reduced slightly (3.4\%) by troglitazone $(8.7 \pm 0.2$ to $8.4 \pm 0.2 \mathrm{mmol} /$ liter, $P=0.02)$ but not by placebo $(8.7 \pm 0.3$ to $8.6 \pm 0.3, P=\mathrm{NS})$. Maximum ISR achieved during glucose infusion was not reduced by troglita- zone $(890 \pm 77$ to $827 \pm 88 \mathrm{pmol} / \mathrm{min}, P=\mathrm{NS})$ or placebo $(957 \pm 153$ to $877 \pm 147, P=$ NS).

The relationship between glucose and ISR throughout the infusion protocol is presented in Fig. 3. As shown, these relationships did not change after treatment when glucose is plotted against ISR (Fig. 3, $A$ and $C$ ). However, since insulin sensitivity changed after treatment with troglitazone, the insulin secretion rates were adjusted for this change, as shown in Fig. 3, $B$ and $D$. After this adjustment, the relationship between glucose and the insulin secretion rate did not change in the pla-
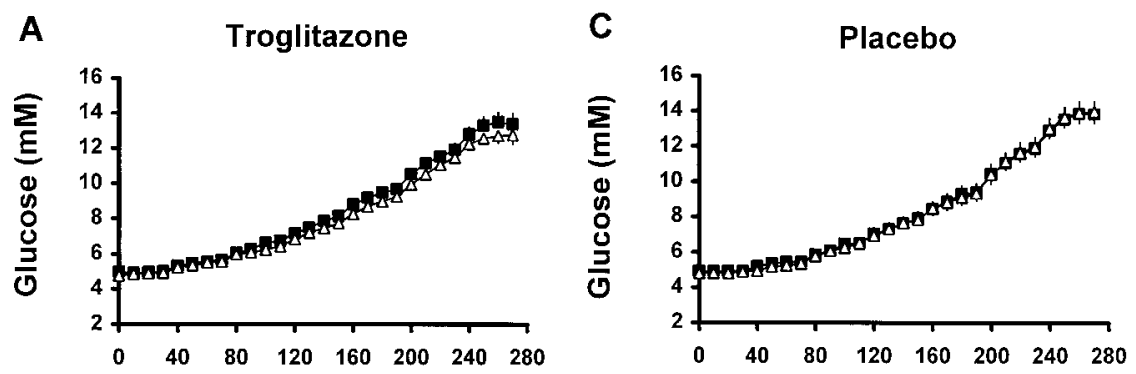

B

D
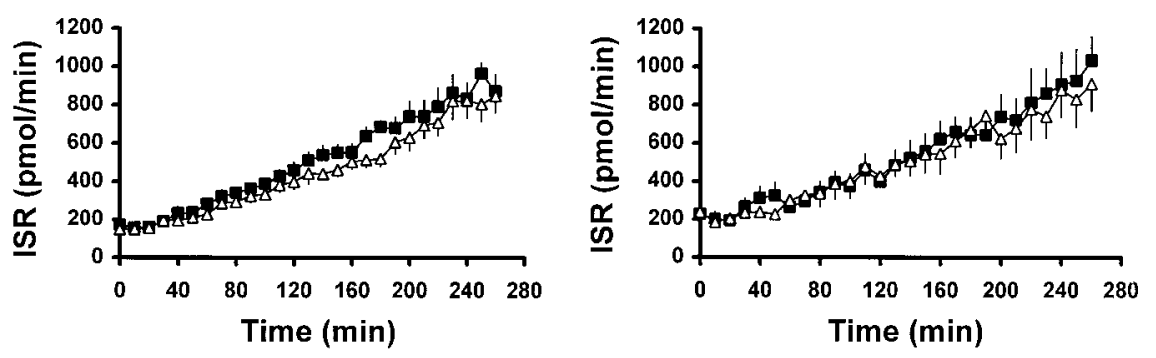

Figure 2. Means of glucose and ISR over time during the graded glucose infusions. Glucose $(A)$ and ISR $(B)$ vs. time before ( $\square)$ and after $(\triangle)$ treatment with troglitazone (left). Glucose $(C)$ and ISR $(D)$ vs. time before $(\boldsymbol{\square})$ and after $(\triangle)$ placebo. Average glucose concentration was reduced by $3.4 \%(P=0.02)$ after troglitazone and was unchanged by placebo. Average ISR did not change in either group. 

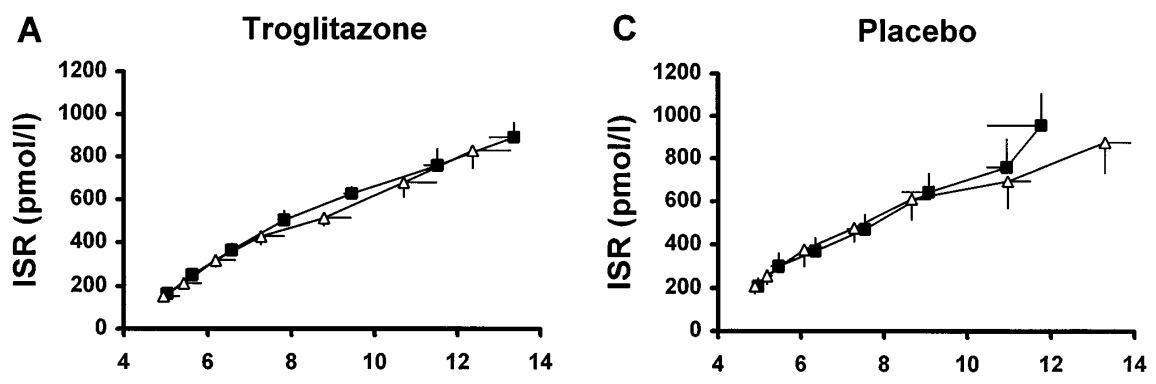

Figure 3. Relationship between glucose and ISR means during the graded glucose infusions. On the left, absolute ISR is plotted against glucose in panel $(A)$ before $(\boldsymbol{\square})$ and
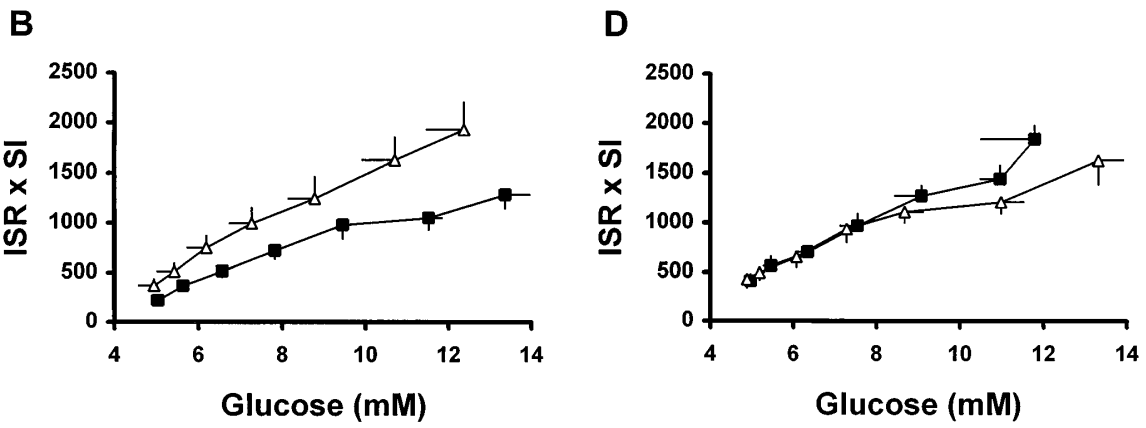
after $(\triangle)$ treatment with troglitazone, and ISR adjusted for insulin sensitivity $\left(\mathrm{S}_{\mathrm{I}}\right)$ is plotted against glucose in panel $(B)$ before $(\square)$ and after $(\triangle)$ troglitazone. The right panel shows absolute ISR against glucose $(C)$ and ISR adjusted for $\mathrm{S}_{\mathrm{I}}$ against glucose $(D)$, before $(\square)$ and after $(\triangle)$ placebo. Average ISR over the range 5-11 $\mathrm{mM}$ glucose was unchanged by placebo. When adjusted for $\mathrm{S}_{\mathrm{I}}$, average ISR over the range $5-11 \mathrm{mM}$ glucose was increased by $52 \%(P=0.02)$ after troglitazone treatment and was unchanged by placebo.

cebo group. However, in the troglitazone treated group $(B)$, the insulin secretory response across a broad range of glucose concentrations, when adjusted for the improvement in insulin sensitivity, increased. Adjusted insulin secretion rates over the interval 5 to $11 \mathrm{mmol} / \mathrm{liter}$ were increased by $52 \%$ in the troglitazone group $(4,456 \pm 598$ vs. $6,781 \pm 1,065 \mathrm{pmol} / \mathrm{min}$ $\left.\left(\times 10^{-5} \mathrm{~min}^{-1} \mathrm{pM}^{-1}\right), P=0.02\right)$ but not in the placebo group $(6,534 \pm 633$ vs. $5,729 \pm 643, P=\mathrm{NS})$, signifying the enhanced ability of the $\beta$ cell to respond to a glucose stimulus over a physiologic range of glucose. This improvement is reflected as the steeper dose-response curve of glucose and insulin secretion shown in Fig. $3 B$.

Relationship between glucose and ISR during oscillatory glucose infusion (Figs. 4 and 5). Representative examples of the profiles of glucose and ISR during the oscillatory glucose infusion protocol are in Figs. 4 and 5 and the results are summarized in Table II. The average glucose levels during these protocols did not change in either the troglitazone $(11.0 \pm 0.6$ to $10.3 \pm 0.6 \mathrm{mmol} / \mathrm{liter}, P=\mathrm{NS})$ or placebo groups $(11.1 \pm 0.9$ to $10.8 \pm 0.9, P=\mathrm{NS}$ ) over the duration of the study. On the other hand, the average ISR was significantly lower in the troglitazone group $(673 \pm 44$ to $605 \pm 38 \mathrm{pmol} / \mathrm{min}, P=0.03)$ at an unchanged glucose concentration but not different in the placebo group $(691 \pm 88$ to $680 \pm 98, P=\mathrm{NS})$. This lowered insulin secretion rate is expected in view of the improvement in insulin sensitivity due to troglitazone treatment. After adjustment for the change in insulin sensitivity, an increase in insulin secretion was observed in the troglitazone-treated group $(1,001 \pm 121$ to $\left.1,465 \pm 195 \mathrm{pmol} / \mathrm{min}\left(\times 10^{-5} \mathrm{~min}^{-1} \mathrm{pM}^{-1}\right), P=0.03\right)$ and no change was seen in the placebo group $(1,464 \pm 160$ to $1,359 \pm 199, P=\mathrm{NS})$.

The example in Fig. 4 shows that following troglitazone treatment, insulin secretory responses to the oscillations in plasma glucose were enhanced resulting in a greater degree of entrainment of insulin secretion by glucose. This was not seen in the placebo treated group (see example in Fig. 5). The effect was quantified by comparing the normalized spectral power of the insulin secretory profiles. The ability of the $\beta$ cell to entrain to an exogenous oscillatory glucose infusion was improved by troglitazone, as measured by normalized spectral power at $144 \mathrm{~min}$ in the treatment group $(5.9 \pm 1.2$ to $8.8 \pm 1.3, P=0.04)$ and was unchanged by the placebo $(5.8 \pm 1.8$ to $5.8 \pm 1.9, P=\mathrm{NS})$.
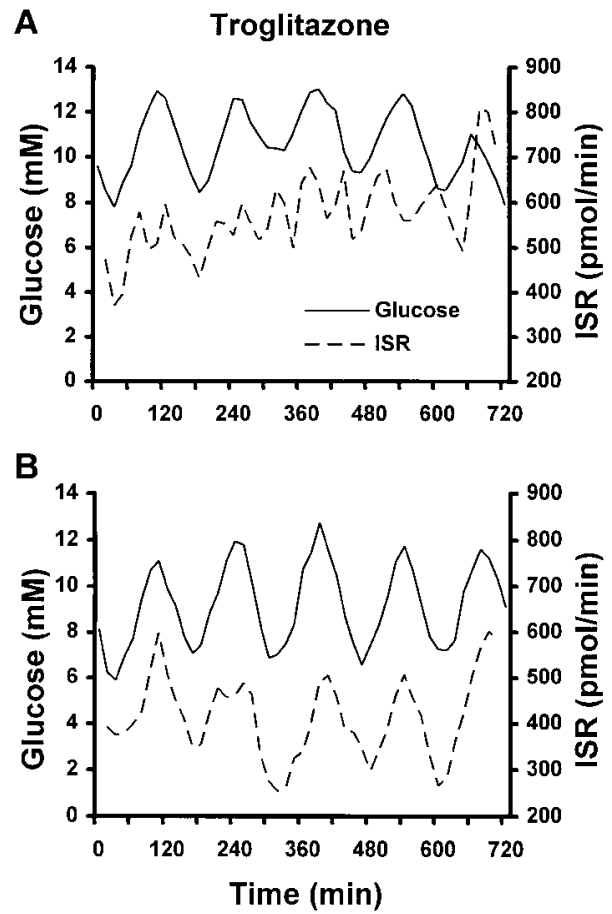

Figure 4. Glucose and ISR profiles during oscillatory glucose infusion. Example of improved entrainment before $(A)$ and after $(B)$ troglitazone. Glucose profiles are shown in solid lines, and ISR profiles are shown in dotted lines. The normalized spectral power increased in this subject from 1.7 to 14.9 . 

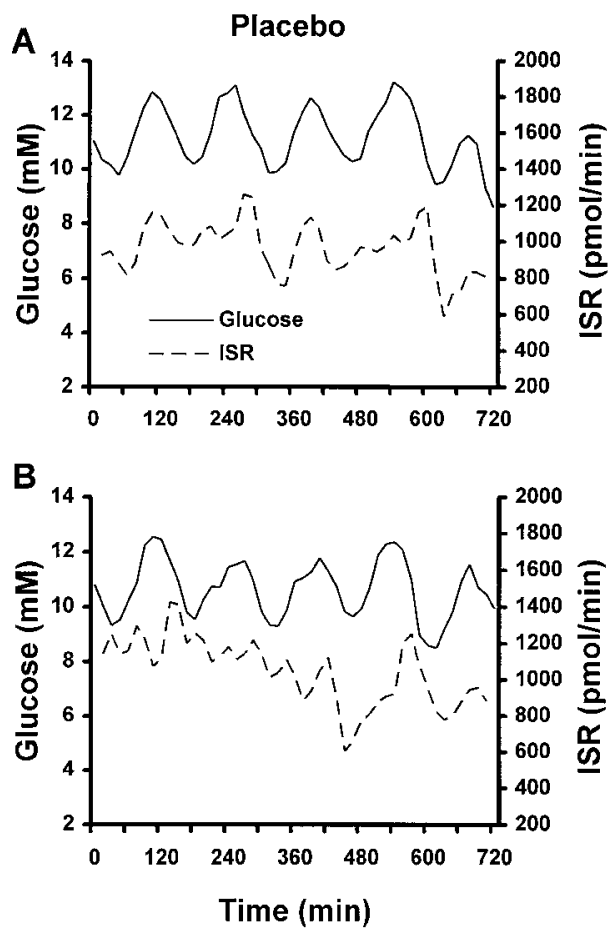

Figure 5. Glucose and ISR profiles during oscillatory glucose infusion. Example of unchanged entrainment before $(A)$ and after $(B)$ placebo. Glucose profiles are shown in solid lines, and ISR profiles are shown in dotted lines. Normalized spectral power was unchanged in this subject (4.1 to 3.6).

\section{Discussion}

Subjects with impaired glucose tolerance have a high rate of progression to overt diabetes (2). IGT can therefore be viewed as a prediabetic state in which defects in both insulin secretion and insulin action, the characteristic features of NIDDM (3639), are already well established. Although drug treatment of IGT is not currently recommended, a major multicenter NIH trial is currently underway to determine whether intensive changes in lifestyle or treatment with metformin or troglitazone will slow the rate of progression to overt diabetes in these subjects. Previous studies in obese diabetic and nondiabetic humans have demonstrated improvements in insulin resistance, overall glucose tolerance, and associated metabolic parameters such as triglycerides and free fatty acids (15-17, 20, 40) with troglitazone. The possibility, however, that beneficial effects on insulin secretion associated with troglitazone treatment contribute to the therapeutic effect of these agents has not been examined. The present study was undertaken to address this issue.

We confirmed the observations of others (15-17) that troglitazone improves oral glucose tolerance and insulin sensitivity. Troglitazone-treated subjects demonstrated a significant reduction in glycemic excursion after oral glucose challenge despite significantly lower insulin levels. Glycohemoglobin values, although normal at baseline, were reduced further. Insulin sensitivity improved, as demonstrated by reduced fasting insulin and a substantial increase in $\mathrm{S}_{\mathrm{I}}$ by the FSIVGTT.

We also demonstrated improvements in the ability of the $\beta$ cell to respond to glucose in the troglitazone-treated subjects, an effect previously observed only in an animal model of diabetes, the Zucker diabetic fatty rat (21-23). This effect was seen during graded and oscillatory glucose infusions. The graded glucose infusion studies define incremental increases in ISR over a standard range of glucose concentrations that correspond to typical postprandial glucose levels. The glucose-ISR dose response curve allows us to examine $\beta$ cell glucose responsiveness at each level of glucose. After adjustment of the insulin secretion rates for the observed changes in insulin sensitivity, insulin secretion at each level of glucose was greatly enhanced, resulting in a steeper dose-response curve, indicative of improved $\beta$ cell glucose responsiveness.

The oscillatory glucose infusion tests the ability of the $\beta$ cell to increase and decrease insulin secretion rapidly in response to parallel changes in plasma glucose, a function requiring intact glucose sensing ability. We have used this protocol previously to document the presence of $\beta$ cell dysfunction in subjects with even mild degrees of glucose intolerance $(9,21)$. The present study demonstrates that treatment with troglitazone significantly improves the ability of the $\beta$ cell to sense changes in plasma glucose as quantified by normalized spectral power.

The analyses that lead us to conclude that troglitazone treatment results in improved beta cell function deserve further comment. We have previously demonstrated that subjects with IGT, when compared to subjects with normal glucose tolerance who are similarly insulin resistant, are characterized by a decrease in the insulin secretory response during a graded glucose infusion and IVGTT $(9,41)$. Thus, in this study, we have expressed measures of insulin secretion in relation to the degree of ambient insulin sensitivity. This adjustment, originally proposed by Bergman (33) as the disposition index, has been subsequently applied to several study populations $(34,42$, 43). Kahn and others (34) have extended this observation by demonstrating a hyperbolic relationship between insulin secretion and sensitivity in a cross-sectional study of normal subjects: with increasing insulin resistance, insulin secretion must rise to maintain stable glucose tolerance. In this study, insulin secretion fell to a lesser extent than would be predicted by this hyperbolic relationship. We interpret this as a relative improvement in $\beta$ cell function that likely contributed to the observed improvement in glucose tolerance. Finally, the enhanced ability to entrain insulin secretion during an oscillatory glucose infusion provides independent confirmation that $\beta$ cell function has improved, using a measure that does not rely on adjustment for changes in insulin sensitivity nor assumes a specific mathematical relationship between insulin secretion and insulin sensitivity.

Thus our results indicate that in addition to enhanced insulin sensitivity, treatment with troglitazone also improves the early $\beta$ cell dysfunction that occurs in subjects with glucose intolerance. A number of possible mechanisms should be considered as being responsible for this therapeutic benefit, including elimination of $\beta$ cell glucotoxicity, improvements in insulin resistance and/or lipid parameters, and previously undocumented effects of troglitazone on the $\beta$ cell.

It has been well documented that a reduction in the plasma glucose concentration in subjects with overt hyperglycemia improves the ability of the $\beta$ cell to respond to a subsequent glucose stimulus (44-46). This has lead to the concept of glucotoxicity, i.e., that prolonged hyperglycemia per se adversely 
affects $\beta$ cell function (47-49). This mechanism is highly unlikely as an explanation for our findings since the subjects in this study were not overtly hyperglycemic; fasting plasma glucose and glycohemoglobin concentrations were within the normal range. Although mild hyperglycemia was seen after glucose challenge, we are unaware of any reports linking such modest alterations in glucose to $\beta$ cell glucotoxicity.

Improvements in insulin resistance with reductions in the degree of compensatory hyperinsulinemia by troglitazone could certainly have contributed to the improvement in $\beta$ cell glucose responsiveness, although the mechanisms involved are uncertain. Chronic compensatory hypersecretion of insulin is an integral feature of insulin resistant states. In certain individuals, failure of $\beta$ cell compensation occurs over time leading to eventual increases in the plasma glucose concentration and the onset of overt diabetes. Although measures to reduce insulin resistance such as increased physical activity $(50,51)$ and weight loss (10) have been demonstrated to reduce the risk of diabetes in insulin resistant individuals, it has not, to our knowledge, been demonstrated previously that specific protection of $\beta$ cell function may be involved in mediating the reduction in diabetes risk. The present study, however, taken in combination with our studies in the rat $(22,23)$, suggest that amelioration of insulin resistance with troglitazone and related thiazolidinediones may protect $\beta$ cell function.

Another possible mechanism for improved $\beta$ cell function in subjects treated with troglitazone relates to the effects of this agent on lipid parameters, most notably triglycerides and free fatty acids. Unfortunately, neither of these metabolites was measured in the present study, although a reduction of both in response to troglitazone treatment has been consistently documented in animal and human studies (17-19). The effects of free fatty acids on insulin secretion are complex (52, 53). Under certain circumstances (e.g., during fasting) they can stimulate and maintain insulin secretion (54). However, there is also increasing evidence that prolonged exposure of the $\beta$ cell to increased concentrations of triglycerides and free fatty acids may result in adverse effects on $\beta$ cell function in much the same manner as do prolonged elevations of plasma glucose, although by different mechanisms (55-57). Troglitazoneinduced reductions in triglycerides and free fatty acids could therefore be responsible for the enhancement in insulin secretion observed in the present study.

Peroxisome proliferator-activated receptor gamma (PPAR $\gamma$ ) is a nuclear hormone receptor expressed predominantly in adipose tissue, where it plays a central role in the control of adipocyte differentiation and gene expression (58-61). PPAR $\gamma$ is expressed in other tissues as well (58). Since thiazolidinediones are selective ligands for PPAR $\gamma(62)$, the possibility that the effects of troglitazone may be related directly or indirectly to increases in the rate of transcription of genes involved in insulin secretion needs to be considered in light of the present findings.

In summary, we confirm previous observations that administration of troglitazone to patients with IGT leads to an improvement in the level of glucose tolerance and a reduction in the severity of the insulin resistance. We have also demonstrated that troglitazone treatment leads to an enhanced ability of the $\beta$ cell to respond to glucose. Taken together, these results suggest that administration of troglitazone to subjects with impaired glucose tolerance may arrest or slow the pathophysiologic mechanisms which underlie the progression from
IGT to frank diabetes and provide a mechanistic framework to study their use in the prevention of NIDDM.

\section{Acknowledgments}

The authors thank Jacqueline Imperial, R.N. and other members of the nursing staff of the Clinical Research Center for expert care of the subjects who participated in the study. The authors thank Jeppe Sturis and Ted Karrison for their expert advice regarding data analysis and Paul Rue and Kimberly Biskup for their excellent technical support.

These studies were supported in part by NIH grants DK-31842, DK-20595, DK-02315, and General Clinical Research Center grant M01 RR00055.

\section{References}

1. Diabetes mellitus: report of a WHO study group. 1985. WHO Tech. Rep. Ser. 727:9-17.

2. Edelstein, S.L., W.C. Knowler, R.P. Bain, R. Andres, E.L. Barrett-Connor, G.K. Dowse, S.M. Haffner, D.J. Pettitt, J.D. Sorkin, D.C. Muller, et al. 1997. Predictors of progression from impaired glucose tolerance to NIDDM. Diabetes. 46:701-710.

3. Lillioja, S., D.M. Mott, B.V. Howard, P.H. Bennett, H. Yki-Järvinen, D. Freymond, B.L. Nyomba, F. Zurlo, B. Swinburn, and C. Bogardus. 1988. Impaired glucose tolerance as a disorder of insulin action. Longitudinal and crosssectional studies in Pima Indians. N. Engl. J. Med. 318:1217-1225.

4. Warram, J.H., B.C. Martin, A.S. Krolewski, J.S. Soeldner, and C.R. Kahn. 1990. Slow glucose removal rate and hyperinsulinemia predict the development of type II diabetes in the offspring of diabetic parents. Ann. Intern. Med. 113:909-915.

5. Haffner, S.M., M.P. Stern, H.P. Hazuda, M.D. Mitchell, and J.P. Patterson. 1988. Increased insulin concentrations in nondiabetic offspring of diabetic parents. N. Engl. J. Med. 319:1297-1301.

6. Eriksson, J., A. Franssila-Kallunki, A. Ekstrand, C. Saloranta, E. Widen, C. Schalin, and L. Groop. 1989. Early metabolic defects in persons at increased risk for non-insulin-dependent diabetes mellitus. N. Engl. J. Med. 321:337-343.

7. O'Rahilly, S., R.C. Turner, and D.R. Matthew. 1988. Impaired pulsatile secretion of insulin in relatives of patients with non-insulin-dependent diabetes mellitus. N. Engl. J. Med. 318:1231-1239.

8. O’Meara, N.M., J. Sturis, E. Van Cauter, and K.S. Polonsky. 1993. Lack of control by glucose of ultradian insulin secretory oscillations in impaired glucose tolerance and in non-insulin-dependent diabetes mellitus. J. Clin. Invest. 92:262-271.

9. Byrne, M.M., J. Sturis, R.J. Sobel, and K.S. Polonsky. 1996. Elevated plasma glucose $2 \mathrm{~h}$ postchallenge predicts defects in $\beta$-cell function. Am. J. Physiol. 270:E572-E579.

10. Long, S.D., K. O’Brien, K.G. MacDonald, N. Leggett-Frazier, Jr., M.S. Swanson, W.J. Pories, and J.F. Caro. 1994. Weight loss in severely obese subjects prevents progression of impaired glucose tolerance to type II diabetes. A longitudinal interventional study. Diabetes Care. 17:372-375.

11. Melander, A., P.-O. Bitzén, G. Sartor, B. Schersten, and E. Wahlin-Boll. 1990. Will sulfonylurea treatment of impaired glucose tolerance delay development and complications of NIDDM? Diabetes Care. 13(Suppl. 3):53-58.

12. Knowler, W.C., G. Sartor, and B. Schersten. 1987. Effects of glucose tolerance and treatment of abnormal tolerance on mortality in Malmohus County, Sweden. Diabetologia. 28:541A. (Abstr.)

13. Rudnichi, A., A. Fontbonne, M. Safar, J.M. Bard, P. Vague, I. JuhanVague, E. Eschwege, and the BIGPRO Study Group. 1994. The effect of metformin on the metabolic anomalies associated with android type body fat distribution. Results of the BIGPRO Trial. Diabetes. (Suppl. 1):150A. (Abstr.)

14. Scheen, A.J., M.R. Letiexhe, and P.J. Lefèbvre. 1995. Short administration of metformin improves insulin sensitivity in android obese subjects with impaired glucose tolerance. Diabetic Med. 12:985-989.

15. Suter, S.L., J.J. Nolan, P. Wallace, B. Gumbiner, and J.M. Olefsky. 1992 Metabolic effects of new oral hypoglycemic agent CS-045 in NIDDM subjects. Diabetes Care. 15:193-203.

16. Nolan, J.J., B. Ludvik, P. Beerdsen, M. Joyce, and J. Olefsky. 1994. Improvement in glucose tolerance and insulin resistance in obese subjects treated with troglitazone. N. Engl. J. Med. 331:1188-1193.

17. Berkowitz, K., R. Peters, S.L. Kjos, J. Goico, A. Marroquin, M.E. Dunn, A. Xiang, S. Azen, and T.A. Buchanan. 1996. Effect of troglitazone on insulin sensitivity and pancreatic $\beta$-cell function in women at high risk for NIDDM. $D i$ abetes. 45:1572-1579.

18. Fujiwara, T., S. Yoshioka, T. Yoshioka, I. Ushiyama, and H. Horikoshi. 1988. Characterization of new oral antidiabetic agent CS-045. Studies in $K K$ and $o b / o b$ mice and Zucker fatty rats. Diabetes. 37:1549-1558.

19. Inoue, I., K. Takahashi, S. Katayama, Y. Harada, K. Negishi, A. Itabshi, 
and J. Ishii. 1995. Effect of troglitazone (CS-045) and bezafibrate on glucose tolerance, liver glycogen synthase activity, and $\beta$-oxidation in fructose-fed rats. Metab. Clin. Exp. 44:1626-1630.

20. Iwamoto, Y., K. Kosaka, T. Kuzuya, Y. Akanuma, Y. Shigeta, and T. Kaneko. 1996. A new hypoglycemic agent in patients with NIDDM poorly controlled by diet therapy. Diabetes Care. 19:151-157.

21. DeSouza, C.J., J.H. Yu, D.D. Robinson, R.G. Ulrich, and M.D. Meglasson. 1995. Insulin secretory defect in Zucker $f a / f a$ rats is improved by ameliorating insulin resistance. Diabetes. 44:984-991.

22. Sturis, J., W.L. Pugh, J. Tang, and K.S. Polonsky. 1995. Prevention of diabetes does not completely prevent insulin secretory defects in the ZDF rat. Am. J. Physiol. 269:E786-E792.

23. Sreenan, S., J. Sturis, W. Pugh, C.F. Burant, and K.S. Polonsky. 1996. Prevention of hyperglycemia in the Zucker diabetic fatty rat by treatment with metformin or troglitazone. Am. J. Physiol. 271:E742-E747.

24. Bergman, R.N. 1989. Lilly Lecture 1989. Toward physiological understanding of glucose tolerance: minimal-model approach. Diabetes. 38:15121527.

25. Byrne, M.M., J. Sturis, K. Clément, N. Vionnet, M.E. Pueyo, M. Stoffel, J. Takeda, P. Passa, D. Cohen, G.I. Bell, et al. 1994. Insulin secretory abnormalities in subjects with hyperglycemia due to glucokinase mutations. J. Clin. Invest. $93: 1120-1130$

26. Byrne, M.M., J. Sturis, and K.S. Polonksy. 1995. Insulin secretion and clearance during low-dose graded glucose infusion. Am. J. Physiol. 268:E21-E27.

27. Sturis, J., E. Van Cauter, J.D. Blackman, and K.S. Polonsky. 1991. Entrainment of pulsatile insulin secretion by oscillatory glucose infusion. J. Clin. Invest. 87:439-445.

28. Morgan, D.R., and A. Lazarow. 1963. Immunoassay of insulin: two antibody system: plasma insulin levels of normal, subdiabetic and diabetic rats. Diabetes. 12:115-125.

29. Faber, O.K., C. Binder, J. Markussen, L.G. Heding, V.K. Naithani, H. Kuzuya, P. Blix, D.L. Horwitz, and A.H. Rubenstein. 1978. Characterization of seven C-peptide antisera. Diabetes. 27(Suppl. 1):170-177.

30. Van Cauter, E., F. Mestrez, J. Sturis, and K.S. Polonksy. 1992. Estimation of insulin secretion rates from C-peptide levels: comparison of individual and standard kinetic parameters for C-peptide clearance. Diabetes. 41:368-377.

31. Eaton, R.P., R.D. Allen, D.S. Schade, K.M. Erickson, and J. Standefer. 1980. Prehepatic insulin production in man: peripheral analysis using connecting peptide behavior. J. Clin. Endocrinol. Metab. 51:520-528.

32. Polonsky, K.S., J. Licinio-Paixao, B.D. Given, W. Pugh, P. Rue, J. Galloway, T. Karrison, and B. Frank. 1986. Use of biosynthetic human C-peptide in the measurement of insulin secretion rates in normal volunteers and type I diabetic patients. J. Clin. Invest. 77:98-105.

33. Bergman, R.N., L.S. Phillips, and C. Cobelli. 1981. Physiologic evaluation of factors controlling glucose tolerance in man. J. Clin. Invest. 68:14561467.

34. Kahn, S.E., R.L. Prigeon, D.K. McCulloch, E.J. Boyko, R.N. Bergman, M.W. Schwartz, J.L. Neifing, W.K. Ward, J.C. Beard, J.P. Palmer, et al. 1993. Quantification of the relationship between insulin sensitivity and $\beta$-cell function in human subjects. Evidence for a hyperbolic function. Diabetes. 42:16631672 .

35. Jenkins, G.M., and D.G. Watts. 1968. Spectral Analysis and Its Applications. Holden Day, San Francisco. 525 pp.

36. Weir, G. 1982. Non-insulin-dependent diabetes mellitus: interplay between $\beta$-cell inadequacy and insulin resistance. Am. J. Med. 73:461-464.

37. Porte, D., Jr. 1991. Banting Lecture 1990. $\beta$-Cells in type II diabetes mellitus. Diabetes. 40:166-180.

38. DeFronzo, R.A., R.C. Bonadonna, and E. Ferrannini. 1992. Pathogenesis of NIDDM. A balanced overview. Diabetes Care. 15:318-368.

39. Polonsky, K.S. 1995. Lilly Lecture 1994. The $\beta$-cell in diabetes: from molecular genetics to clinical research. Diabetes. 44:705-717.

40. Iwamoto, Y., T. Kuzuya, A. Matsuda, T. Awata, S. Kumakura, G. Inooka, and I. Shiraishi. 1991. Effect of new oral antidiabetic agent CS-045 on glucose tolerance and insulin secretion in patients with NIDDM. Diabetes Care. 14:1083-1086.

41. Ehrmann, D.A., J. Sturis, M.M. Byrne, T. Karrison, R.L. Rosenfield, and K.S. Polonsky. 1995. Insulin secretory defects in polycystic ovary syndrome. J. Clin. Invest. 96:520-527.

42. Dunaif, A., and D.T. Finegood. 1996. $\beta$-cell dysfunction independent of obesity and glucose intolerance in the polycystic ovary syndrome. J. Clin. Endocrinol. Metab. 81:942-947.

43. Dunaif, A., D. Scott, D. Finegood, B. Quintana, and R. Whitcomb. 1996. The insulin-sensitizing agent troglitazone improves metabolic and reproductive abnormalities in the polycystic ovary syndrome. J. Clin. Endocrinol. Metab. 81:3299-3306.

44. Kosaka, K., T. Kuzuya, Y. Akanuma, and R. Hagura. 1980. Increase in insulin response after treatment of overt maturity-onset diabetes is independent of the mode of treatement. Diabetologia. 18:23-28.

45. Vague, P., and J.P. Moulin. 1982. The defective glucose sensitivity of the $\beta$-cell in non insulin dependent diabetes. Improvement after twenty hours of normoglycaemia. Metab. Clin. Exp. 31:139-142.

46. Hidaka, H., M. Nagulesparan, I. Klimes, R. Clark, H. Sasaki, S.L. Aronoff, B. Vasquez, A.H. Rubenstein, and R.H. Unger. 1985. Improvement of insulin secretion but not insulin resistance after short term control of plasma glucose in obese type II diabetics. J. Clin. Endocrinol. Metab. 54:217-222.

47. Rosetti, L., A. Giaccari, and R.A. DeFronzo. 1990. Glucose toxicity. Diabetes Care. 13:610-629.

48. Leahy, J.L., S. Bonner-Weir, and G.C. Weir. 1992. $\beta$-Cell dysfunction induced by chronic hyperglycemia: current ideas on mechanism of impaired glucose-induced insulin secretion. Diabetes Care. 15:442-453.

49. Yki-Järvinen, H. 1992. Glucose toxicity. Endocrine Rev. 13:415-431.

50. Helmrich, S.P., D.R. Ragland, R.W. Leung, and R.S. Paffenbarger, Jr. 1991. Physical activity and reduced occurrence of non-insulin-dependent diabetes mellitus. N. Engl. J. Med. 325:147-152.

51. Eriksson, K.F., and F. Lindgarde. 1991. Prevention of type II (non-insulin-dependent) diabetes mellitus by diet and physical exercise:the 6-year Malmo feasibility study. Diabetologia. 34:891-898.

52. McGarry, J.D. 1994. Disordered metabolism in diabetes: have we underemphasized the fat component? J. Cell. Biochem. 55S:29-38.

53. Unger, R.H. 1995. Lipotoxicity in the pathogenesis of obesity-dependent NIDDM. Diabetes. 44:863-870.

54. Stein, D.T., V. Esser, B.E. Stevenson, K.E. Lane, J.H. Whiteside, M.B Daniels, S. Chen, and J.D. McGarry. 1996. Essentiality of circulating fatty acids for glucose-stimulated insulin secretion in the fasted rat. J. Clin. Invest. 97: $2728-2735$.

55. Sako, Y., and V.E. Grill. 1990. A 48-hour lipid infusion in the rat timedependently inhibits glucose-induced insulin secretion and $\beta$-cell oxidation through a process likely coupled to fatty acid oxidation. Endocrinology. 127: $1580-1589$.

56. Elks, M.L. 1993. Chronic perifusion of rat islets with palmitate suppresses glucose-stimulated insulin release. Endocrinology. 133:208-214.

57. Zhou, Y.-P., and V.E. Grill. 1994. Long-term exposure of rat pancreatic islets to fatty acids inhibits glucose-induced insulin secretion and biosynthesis through a glucose fatty acid cycle. J. Clin. Invest. 93:870-876.

58. Keller, H., and W. Wahli. 1993. Peroxisome proliferator-activated receptors: A link between endocrinology and nutrition? Trends Endocrinol. Metab. 4:291-296.

59. Ibrahimi, A., L. Teboul, D. Gaillard, E.Z. Amri, G. Ailhaud, P. Young, M.A. Cawthorne, and P.A. Grimaldi. 1994. Evidence for a common mechanism of action for free fatty acids and thiazolidinedione antidiabetic agents on gene expression in preadipose cells. Mol. Pharmacol. 46:1070-1076.

60. Brandes, R., R. Arad, and J. Bar-Tana. 1995. Inducers of adipose conversion activate transcription promoted by a peroxisome proliferators response element in 3T3-L1 cells. Biochem. Pharmacol. 50:1949-1951.

61. Kliewer, S.A., J.M. Lenhard, T.M. Willson, I. Patel, D.C. Morris, and J.M. Lehmann. 1995. A prostaglandin $\mathbf{J}_{2}$ metabolite binds peroxisome proliferator-activated receptor $\gamma$ and promotes adipocyte differentiation. Cell. 83:813-819.

62. Lehmann, J.M., L.B. Moore, T.A. Smith-Oliver, W.O. Wilkinson, T.M. Willson, and S.A. Kliewer. 1995. An antidiabetic thiazolidinedione is a high affinity ligand for peroxisome proliferator-activated receptor $\gamma(\operatorname{PPAR} \gamma)$. J. Biol. Chem. 270:12953-12956. 